Research Paper

\title{
Cinnamomum Cassia Extracts Suppress Human Lung Cancer Cells Invasion by Reducing u-PA/MMP Expression through the FAK to ERK Pathways
}

\author{
Hsing-Chen $\mathrm{Wu}^{1}$, Chi-Ting Horng, 3*, You-Li Lee ${ }^{4}$, Pei-Ni Chen ${ }^{3}, 5$, Chin-Yin Lin ${ }^{3}$, Chen-Yu Liao ${ }^{3}$, Yih-Shou \\ $\mathrm{Hsieh}^{3,5}$, Shu-Chen $\mathrm{Chu}^{6}$
}

1. Department of Nutrition, Kaohsiung Armed Forces General Hospital, Kaohsiung City, Taiwan, ROC;

2. Departmant of Ophthalmology, Kaohsiung Armed Forces General Hospital, Kaohsiung, Taiwan;

3. Institute of Biochemistry, Microbiology and Immunology, Chung Shang Medical University, Taichung City, Taiwan;

4. Department of Nutrition, Kaohsiung Armed Forces General Hospital, Kaohsiung City, Taiwan, ROC;

5. Clinical Laboratory, Chung Shan Medical University Hospital, Taichung, Taiwan;

6. Institute and Department of Food Science, Central Taiwan University of Science and Technology, Taichung, Taiwan.

* Chi-Ting Horng contributed equally as first author.

$\triangle$ Corresponding authors: Shu-Chen Chu, Ph.D., Institute and Department of Food Science, Central Taiwan University of Science and Technology, No. 11 Pu-tzu Lane, Pu-tzu Road, Taichung 406, Taiwan. Telephone: +886-4-2239-1647 ext 3504, E-mail: scchu@ctust.edu.tw; Yih-Shou Hsieh, Ph.D., Institute of Biochemistry, Microbiology and immunology, Chung Shan Medical University, No 110, Section 1, Chien Kuo N. Road, Taichung 402, Taiwan, Telephone: +886-4-2473-0022 ext 11678, E-mail: csmcysh@csmu.edu.tw

(C) Ivyspring International Publisher. This is an open access article distributed under the terms of the Creative Commons Attribution (CC BY-NC) license (https://creativecommons.org/licenses/by-nc/4.0/). See http://ivyspring.com/terms for full terms and conditions.

Received: 2017.08.09; Accepted: 2017.11.13; Published: 2018.01.01

\begin{abstract}
Cinnamomum cassia exhibits antioxidative, apoptotic, and cytostatic properties. These activities have been attributed to the modulation of several biological processes and are beneficial for possible pharmaceutical applications. However, the potential of $C$. cassia in retarding lung adenocarcinoma cells metastasis remains ambiguous. We determined whether $C$. cassia extract (CCE) reduces metastasis of human lung adenocarcinoma cells. The results showed that CCE treatment (up to 60 $\mu \mathrm{g} / \mathrm{mL}$ ) for $24 \mathrm{~h}$ exhibited no cytotoxicity on the A549 and H1299 cell lines but inhibited the motility, invasiveness, and migration of these cells by repressing matrix metalloproteinase (MMP)-2 and urokinase-type plasminogen activator (u-PA). CCE also impaired cell adhesion to collagen. CCE significantly reduced p-focal adhesion kinase (FAK) Tyr397, p-FAK Tyr925, p-extracellular signal-regulated kinases (ERK) $1 / 2$, and Ras homolog gene family (Rho)A expression. CCE showed anti-metastatic activity of A549 and H1299 cells by repressing u-PA/MMP-2 via FAK to ERK1/2 pathways. These findings may facilitate future clinical trials of lung adenocarcinoma chemotherapy to confirm the promising results.
\end{abstract}

Key words: FAK; ERK; metastasis; lung cancer; Cinnamomum cassia.

\section{Introduction}

Metastasis is one of the hallmarks of cancer cells and involves a series of complex processes of cancer cells. These processes include the acquisition of motility, local invasion and entrance into the systemic blood circulation, survival in circulation, and subsequent extravasation and growth at distant organs [1]. Additionally, extracellular protease secretion and degradation of the extracellular matrix (ECM) play an important role in cancer invasion.
Among these proteases, matrix metalloproteinase (MMP)-2, MMP-9, and urokinase-type plasminogen activator (u-PA) play the most important roles in tumor cell invasion and metastasis.

Chemoprevention is the single or combined use of natural or synthetic agents to prevent, delay, reverse, or reduce the tumorigenic process. This therapy is a promising area of current cancer research. C. cassia is a common food spice and presents 
medicinal properties, such as antiviral [2], antioxidant [3], and anti-tumorigenic [4] activities. Earlier reports have indicated that C. cassia primarily contains vital oils and other derivatives, such as cinnamaldehyde, cinnamic acid, cinnamyl alcohol, cinnamate and coumarin [5-7]. C. cassia essential oil could inhibit cell proliferation and induce apoptosis in human oral cancer HSC-3 cells [4]. However, the effect of C. cassia on the metastasis and invasion of lung cancer cells and the underlying mechanisms of such effect remain unclear. In this study, we proposed that $C$. cassia may affect lung adenocarcinoma cells to exert anti-cancer effects. Metastasis is caused by numerous factors. Thus, additional experiments were designed to clarify the detailed mechanism of $C$. cassia in inhibiting the invasion and migration of lung cancer cells.

\section{Material and Methods}

\section{Preparation of $C$. cassia extract (CCE)}

C. cassia was purchased from a store in Taichung, Taiwan, and CCE was prepared as previously described [8]. Air-dried branches (100 g) were boiled at $70{ }^{\circ} \mathrm{C}$ for $24 \mathrm{~h}$ with $500 \mathrm{~mL}$ of $50 \%$ ethanol. Then, the solvent was removed, and the filtrate was lyophilized and stored at $-20^{\circ} \mathrm{C}$. The recovery ratio of CCE is $17.25 \%$.

\section{Cell culture}

A549 (human lung adenocarcinoma cell line), H1299 (human lung adenocarcinoma cell line), WI-38 (human lung fibroblast cell line), and MRC-5 (normal human fetal lung fibroblast) cell lines were obtained from American Type Culture Collection (Manassas, VA) and cultured in Dulbecco's Modified Eagle's medium (DMEM; for A549 and H1299) or Basal Medium Eagle (BME; for MRC-5 and WI-38) supplemented with $10 \%$ fetal bovine serum (FBS), $2 \mathrm{mM}$ glutamine, $100 \mathrm{U} / \mathrm{mL}$ penicillin, and 100 $\mu \mathrm{g} / \mathrm{mL}$ streptomycin. All cell cultures were maintained at $37^{\circ} \mathrm{C}$ in a humidified atmosphere of $5 \%$ $\mathrm{CO}_{2}$.

\section{Wound healing assay}

We determined whether CCE could alter the migration of A549 and H1299 cells. We plated 1.0 $\times 10^{4}$ A549 or H1299 cells in six-well plates for $24 \mathrm{~h}$. The cells were wounded by scratching with a pipette tip, then incubated with DMEM containing 0.5\% FBS, and treated with different concentrations of CCE for 0,24 , and $48 \mathrm{~h}$. Cells were photographed using a phase-contrast microscope $(\times 100)$ as described elsewhere $[9,10]$.

\section{Microculture tetrazolium (MTT) assay}

Cells were seeded onto 24 -well plates at a density of $3 \times 10^{4}$ cells/well and treated with CCE at a concentration of $0-60 \mu \mathrm{g} / \mathrm{mL}$ at $37^{\circ} \mathrm{C}$ for 24 and $48 \mathrm{~h}$. After the exposure period, media were removed and cells were washed with phosphate-buffered saline followed by incubation with $0.5 \mathrm{mg} / \mathrm{mL}$ MTT in culture medium for an additional $4 \mathrm{~h}$. The blue formazan crystals of viable cells were dissolved and measured spectrophotometrically at $570 \mathrm{~nm}$ [11].

\section{Boyden chamber cell invasion and motility assays}

After pre-treatment with CCE for $24 \mathrm{~h}$, the cells were harvested and seeded to the Boyden chamber (Neuro Probe, Cabin John, MD) at $1.5 \times 10^{4}$ cells/well in serum-free medium and then incubated for another $24 \mathrm{~h}$ at $37^{\circ} \mathrm{C}$. For the invasion assay, $10 \mu \mathrm{L}$ of Matrigel $(0.5 \mathrm{mg} / \mathrm{mL})$ was applied to polycarbonate membrane filters ( $8 \mu \mathrm{m}$ pore size), with the bottom chamber of the apparatus containing standard medium $(10 \%$ FBS DMEM medium). The invaded cells were fixed with methanol and stained with Giemsa. Cell numbers were counted using a light microscope, whereas motility assay was performed as described for the invasion assay, without Matrigel coating [12].

\section{Cell-matrix adhesion assay}

After treatment with CCE for $24 \mathrm{~h}$, the cells were placed on 24-well dishes coated with collagen type I or gelatin $(10 \mu \mathrm{L} / \mathrm{mL})$. The cells were washed by phosphate-buffered saline to remove nonadherent cells. After staining with $0.1 \%$ crystal violet, fixed cells were lysed in $0.2 \%$ Triton $\mathrm{X}-100$, and the absorbance was measured at $550 \mathrm{~nm}$ [12].

\section{Determination of MMPs and u-PA by zymography}

Cells were treated with CCE $(0,20,40$, and 60 $\mu \mathrm{g} / \mathrm{mL}$ ) for 24 and $48 \mathrm{~h}$. After indicated treatments, the conditioned media were collected, centrifuged to remove any cellular contaminants and stored at $-80^{\circ} \mathrm{C}$ until use. Collected media were prepared with sodium dodecyl sulphate (SDS) sample buffer without boiling or reduction and subjected to gelatin zymography and casein zymography analysis to determine the MMPs and u-PA, respectively. For gelatin zymography, collected media were subjected to $0.1 \%$ gelatin- $8 \%$ SDS polyacrylamide gel electrophoresis to determine the MMPs. The gels were washed with $2.5 \%$ Triton X-100 after electrophoresis and then incubated in the reaction buffer. The gel was then stained with Coomassie brilliant blue R-250, and u-PA activity was visualized by casein zymography $[9,10,13] .2 \% \mathrm{w} / \mathrm{v}$ casein and $20 \mu \mathrm{g} / \mathrm{mL}$ plasminogen were added to $8 \%$ SDS-PAGE gels. u-PA activity of cells treated or untreated with CCE was measured as 
described in the gelatin zymography.

\section{Western blot analysis}

After treatment with different concentrations of CCE for $24 \mathrm{~h}$, the total cell lysates were prepared as described elsewhere [11]. The total cell lysates were incubated with the p-FAK, total-FAK, p-ERK1/2, total-ERK1/2, PI3K and RhoA primary antibodies (Cell Singling Technology, Inc., Danvers, MA, USA), washed, and monitored by immunoblot assays using specific secondary antibodies. The relative photographic densities were quantified by scanning the photographic negatives using a gel documentation and analysis system (Alpha-Imager 2000, Alpha Innotech Corporation, San Leandro, CA, USA). After measuring the intensity of each band by densitometry, relative intensities were calculated by normalizing to GAPDH from the corresponding sample.

\section{Statistical analysis}

Statistical significances were analyzed by one-way ANOVA with post hoc Dunnett's test. P value $<0.05$ was considered statistically significant (Sigma-Stat 2.0, Jandel Scientific, San Rafael, CA).

\section{Results}

\section{CCE treatment of up to $60 \mu \mathrm{g} / \mathrm{mL}$ for $24 \mathrm{~h}$ has no cytotoxic effect on A549 and H1299 cells}

Viability of A549 and H1299 cells after 24 h of CCE treatment $(10,20$, and $60 \mu \mathrm{g} / \mathrm{mL})$ was not significantly different with that of control $(0 \mu \mathrm{g} / \mathrm{mL})$, whereas $48 \mathrm{~h}$ of $60 \mu \mathrm{g} / \mathrm{mL}$ CCE treatment resulted in a decline in cell viability of H1299 cells (Figures 1A and 1B). Thus, $24 \mathrm{~h}$ of CCE treatment up to $60 \mu \mathrm{g} / \mathrm{mL}$ had no cytotoxic effect on A549 and H1299 cells. We used this concentration range for $24 \mathrm{~h}$ of CCE treatment in all subsequent experiments to investigate the anti-invasive property of CCE. Using the same procedures, we found that this compound did not exert any significant cytotoxicity on nonmalignant human fetal lung fibroblast MRC-5 (Figure 1C) and nonmalignant human lung fibroblast cell line WI-38 (Figure 1D).

\section{CCE inhibits A549 and H1299 cell migration}

CCE (up to $60 \mu \mathrm{g} / \mathrm{mL}$ ) significantly attenuated cell migration dose-dependently in A549 (Figure 1E) and H1299 (Figure 1F) cells in the wound healing assay.

\section{CCE inhibits A549 and H1299 cells invasiveness and motility}

Whether CCE also suppressed human lung adenocarcinoma A549 and H1299 cellular motility potential and invasive activity was also determined by conducting Boyden chamber invasion and motility assays. Both modified Boyden chamber with or without Matrigel assays showed that CCE significantly inhibited the invasive (Figures 2A and 2B) activity and motility potential of A549 and H1299 cells dose-dependently (Figures 2C and 2D). Therefore, CCE could be considered to decrease the metastatic activity of A549 and H1299 cells.

\section{CCE inhibits MMP-2 and u-PA of A549 and H1299 cells}

The results from the gelatin zymography show that CCE inhibited the MMP-2 level for 24 and $48 \mathrm{~h}$ in A549 and H1299 cells, respectively (Figures 3A and 3B). In addition to MMP-2, CCE inhibited the expression of the upper stream u-PA for 24 and $48 \mathrm{~h}$ in both cells (Figures 3C and 3D).

\section{CCE reduces cell-matrix adhesion to gelatin and collagen in A549 and H1299 cells}

We also assessed whether CCE regulated cell adhesion to extracellular matrix components. Cells were pre-treated with different concentrations $(0,20$, 40 , and $60 \mu \mathrm{g} / \mathrm{mL}$ ) of CCE prior to the adhesion assay on gelatin (heat-denatured collagen, $\alpha_{5} \beta_{3}$-ligand) and collagen type 1 ( $\alpha_{2} \beta_{1}$-ligand). CCE impaired cell adhesion to gelatin (Figures $4 \mathrm{~A}$ and $4 \mathrm{~B}$ ) and collagen type 1(Figures $4 \mathrm{C}$ and $4 \mathrm{D}$ ) in both cell lines.

\section{CCE decreases FAK and ERK $1 / 2$ phosphorylation of A549 cells}

Western blot analysis was performed to investigate the molecular mechanisms. Compared with the control group, CCE significantly reduced p-FAK Tyr397 and p-FAK Tyr925 expression, but had no effect on t-FAK expression (Figure 4E). These results indicated that $\mathrm{p}$-FAK and $\mathrm{p}$-ERK1/2 could mediate the anti-metastasis mechanism of CCE in A549 cells. The signaling transduction proteins ERK1/2 were investigated to confirm whether the expression of FAK downstream was altered. Consequently, expression of phosphorylated ERK1/2 were markedly reduced by CCE in A549 cells, while total protein expression of ERK1/2 was unchanged (Figure 5A). These results suggested the involvement of FAK and ERK1/2 signaling pathways in the role of CCE on A549 cells. 
A

A549

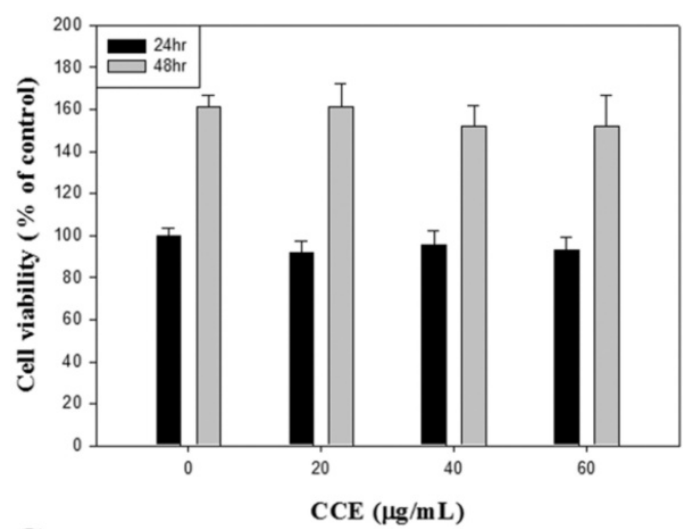

C

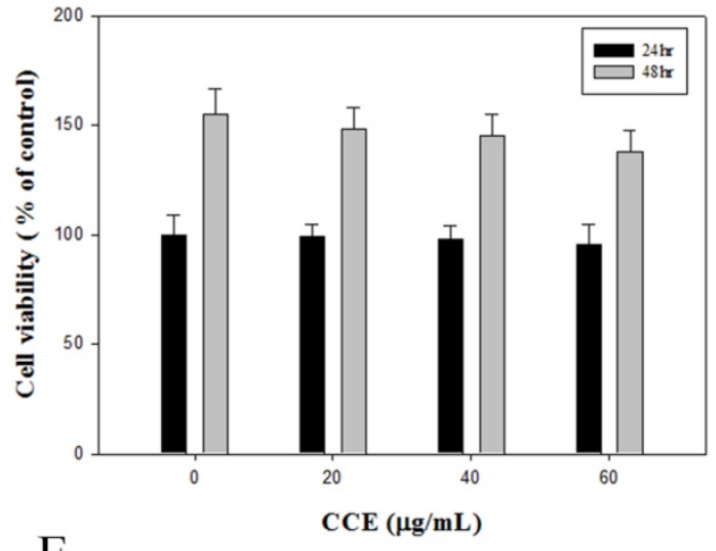

E

A549
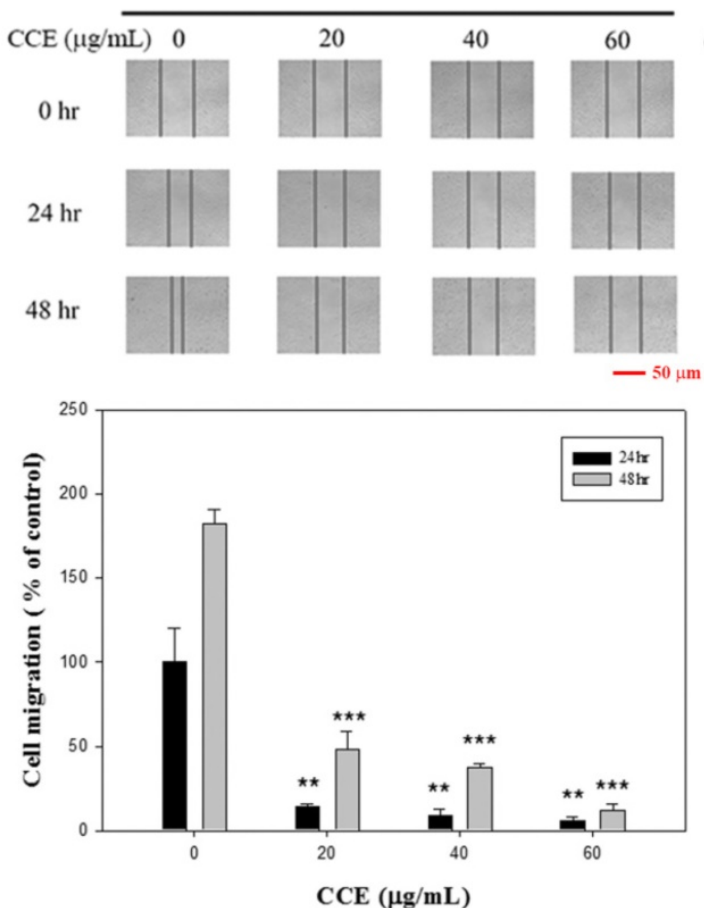

B

H1299

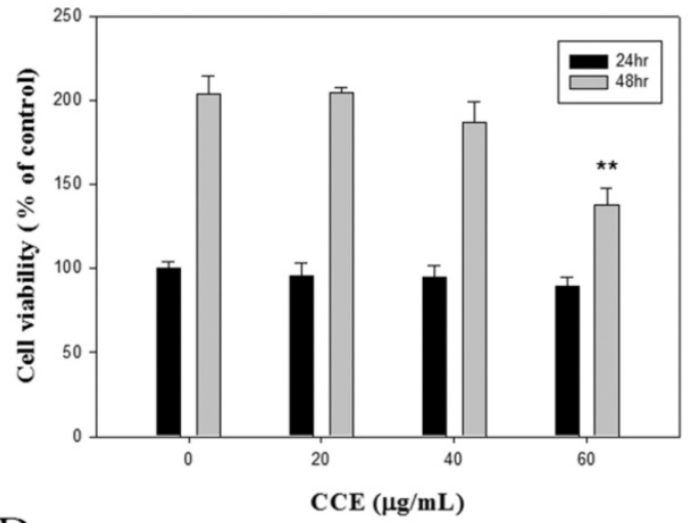

D

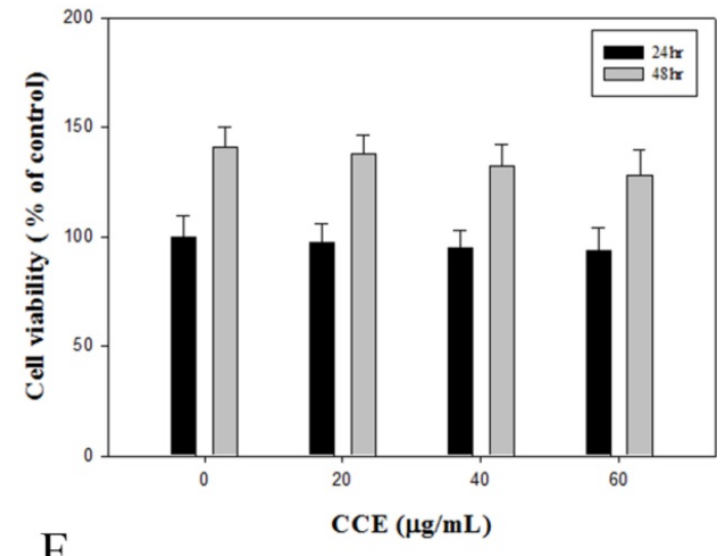

F

H1299
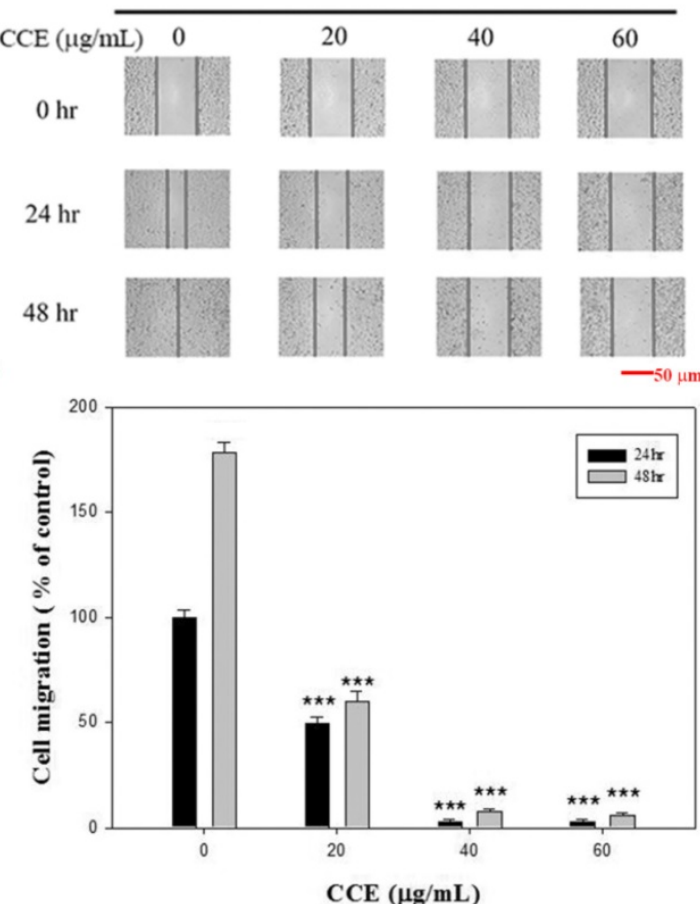

Figure 1. Effects of CCE on cell viability and wound healing assay in human lung cancer A549 and H1299 cells. (A) A549 (B) H1299 (C) MRC-5 and (D) WI-38 cells were treated with different concentrations $(0,20,40$, and $60 \mu \mathrm{g} / \mathrm{mL})$ of CCE for 24 and $48 \mathrm{~h}$ prior to MTT assay for cell viability. The wound healing assay was conducted as described in the Materials and Methods section after (E) A549 and (F) HI 299 cells were treated with different concentrations $(0,20,40$, and $60 \mu \mathrm{g} / \mathrm{mL})$ of CCE for 24 and $48 \mathrm{~h}$. micrograph: $40 \times$. Scale bar, $50 \mu \mathrm{m}$. Results were statistically evaluated using one-way ANOVA with post hoc Dunnett's test (**, $P<0.01$; ***, $P<0.001)$. Results from three repeated and separate experiments were similar. 
A

$\mathrm{CCE}(\mu \mathrm{g} / \mathrm{mL})$

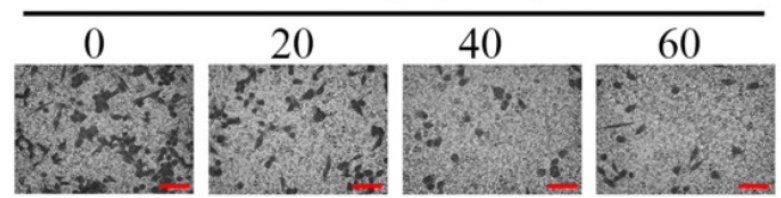

A549

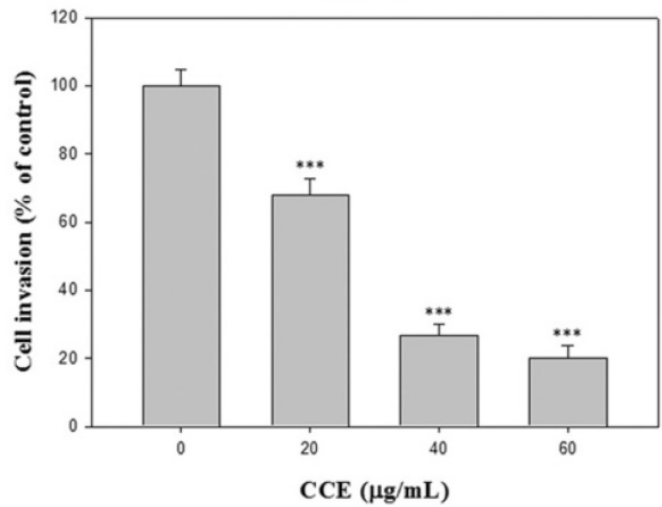

C

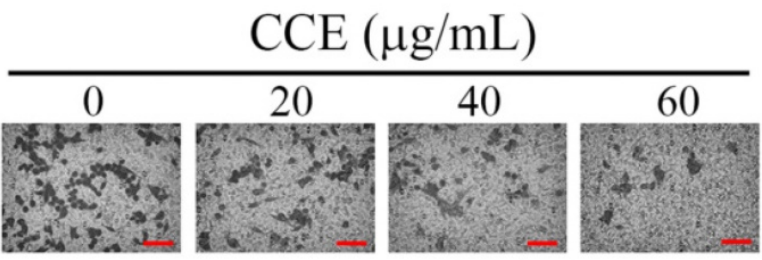

A549

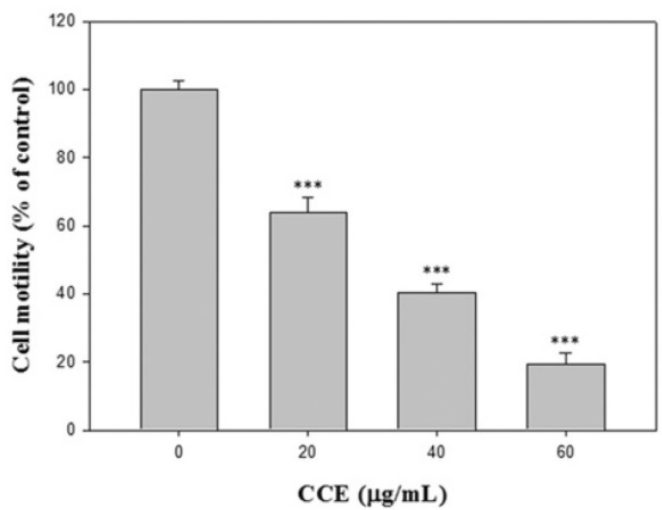

B

CCE $(\mu \mathrm{g} / \mathrm{mL})$

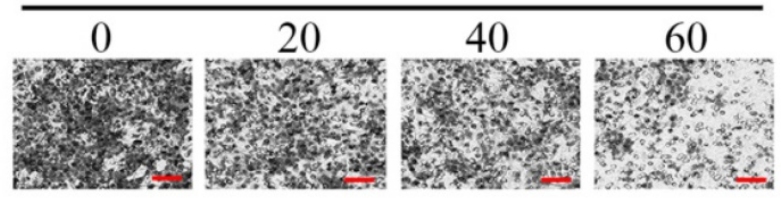

H1299

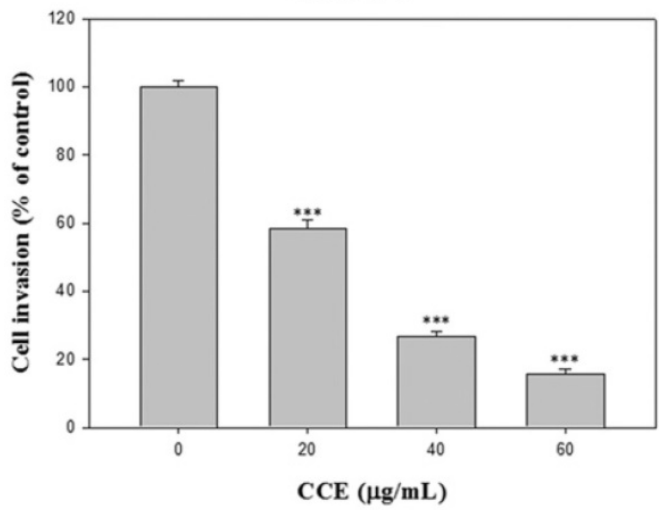

D

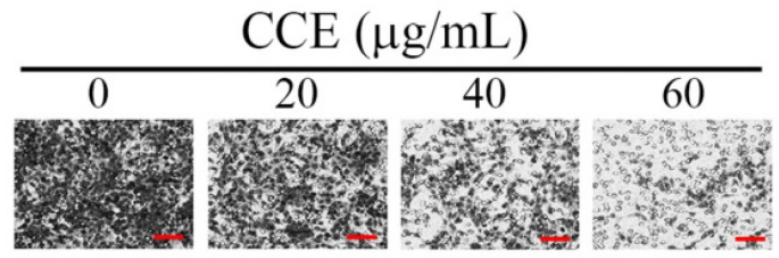

H1299

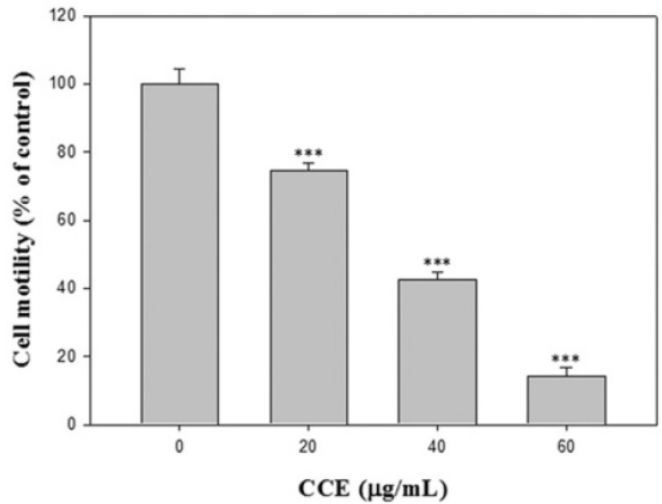

Figure 2. Effects of CCE on the cell motility and invasion assays in human lung cancer A549 and H1299 cells. Cell invasion (A and B) and motility (C and D) assays in $\mathrm{A} 549$ cells and $\mathrm{H} 1299$ cells were measured after the cells were treated with different concentrations $(0,20,40$, and $60 \mu \mathrm{g} / \mathrm{mL})$ of $\mathrm{CCE}$ for $24 \mathrm{~h}$. micrograph: $100 \times$. Scale bar, $100 \mu \mathrm{m}$. Data represent mean \pm SD, with that of control as $100 \%$. Statistical significance of the results was analyzed using one-way ANOVA with post hoc Dunnett's test (*, $P<0.05 ; * *, P<0.01 ; * * *, P<0.001)$.

\section{CCE inhibits RhoA protein expression of A549 cell}

In-depth investigation of the molecular mechanisms revealed that $\mathrm{CCE}$ reduced the expression of RhoA but had no obvious influence on the expression of PI3K in A549 cells (Figure 5B). These results suggest that RhoA may have crucial roles in
CCE inhibition of A549 cells motility, migration, and invasion.

In summary, these findings suggested that $\mathrm{CCE}$ could inhibit the invasion and migration via downregulation of the phosphorylation of ERK1/2 and FAK and activities of MMP-2 and u-PA in human lung A549 and H1299 cells (Figure 6). 


\section{Discussion}

Metastasis of lung cancer is the most important cause of patient death, and various treatments have targeted the prevention of metastasis. This study investigated the anti-cancer effects of CCE on lung cancer. We provided clear evidence that CCE, at concentrations without cytotoxicity (up to $60 \mu \mathrm{g} / \mathrm{mL}$ for $24 \mathrm{~h}$ ), suppressed tumor cell migratory, motility, and invasiveness potential in A549 and H1299 cells. Tumor cell invasion requires cell invasion and digestion of the basement membrane and the extracellular matrix by MMPs and u-PA [14-16]. Thus, we hypothesized that CCE could affect one of these mechanisms in lung adenocarcinoma cells. CCE suppressed the u-PA and MMP-2 activities in both cell lines.
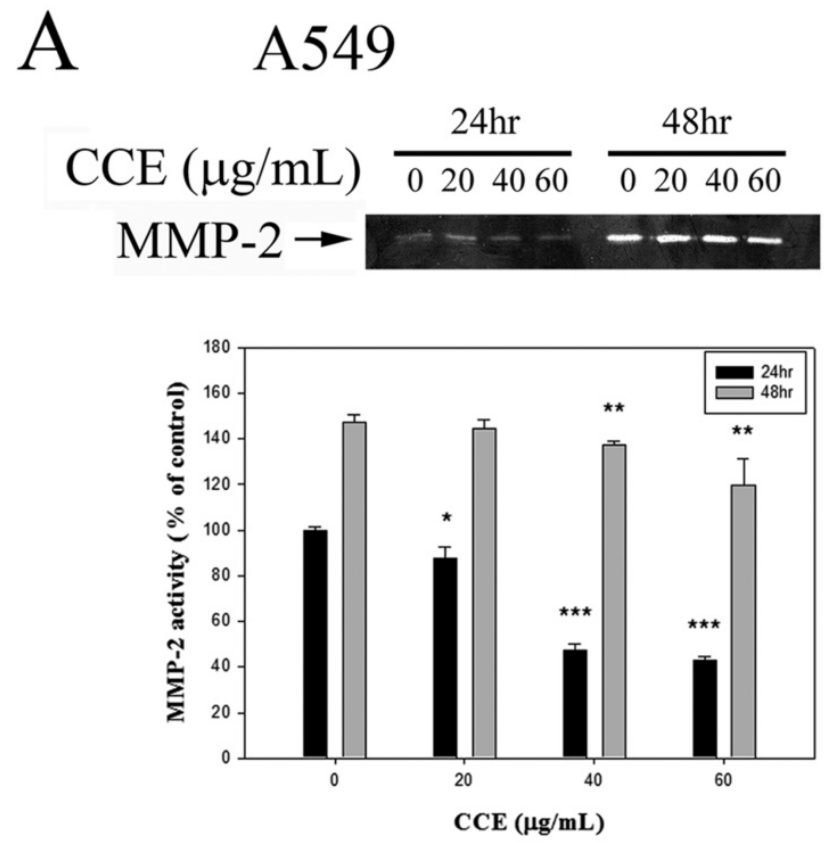

C
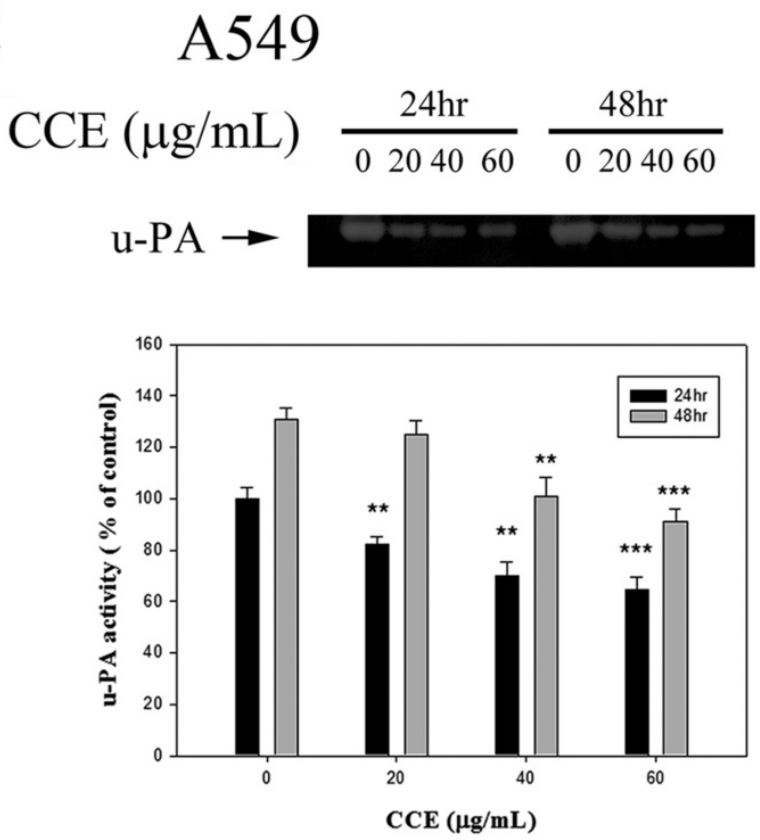

B $\mathrm{H} 1299$
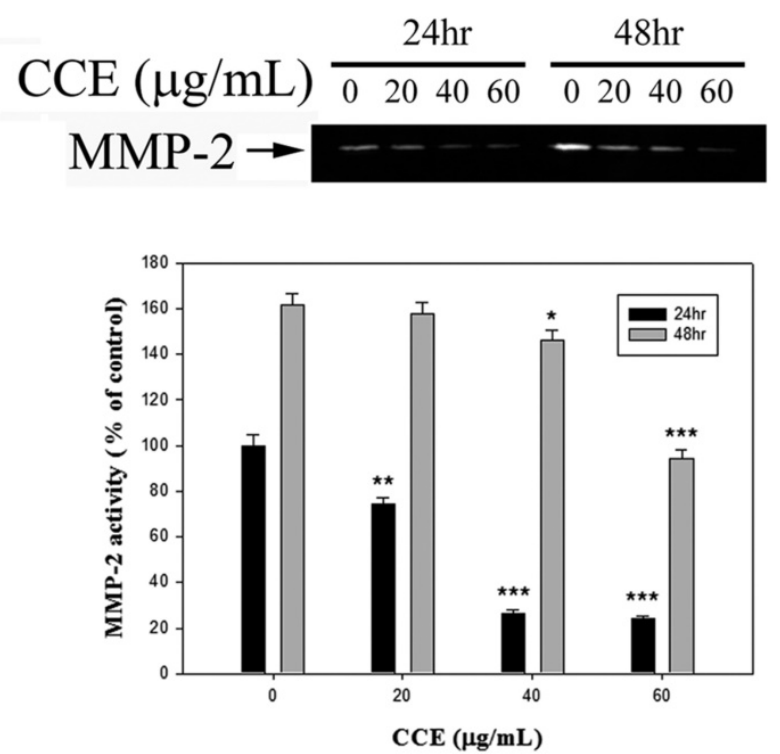

D H1299
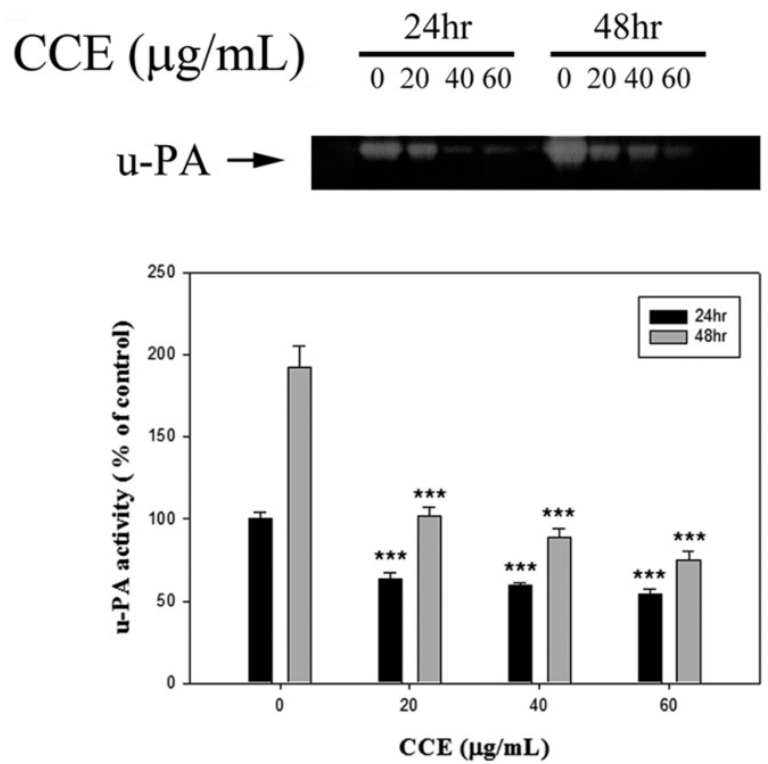

Figure 3. Effects of CCE on MMP-2 and u-PA in human lung cancer A549 and H1299 cells. Activities of MMP-2 were measured by gelatin zymography after the (A) A549 and (B) H1299 cells were treated with different concentrations (0,20,40, and $60 \mu \mathrm{g} / \mathrm{mL})$ of CCE for 24 and $48 \mathrm{~h}$ in. (C) A549 and (D) H1299 cells were treated with CCE for 24 and $48 \mathrm{~h}$ and then subjected to casein zymography to analyze the activities of u-PA, as described in Materials and Methods. Data represented mean $\pm \mathrm{SD}$, with that of control as $100 \%$. Statistical significance of results was analyzed using one-way ANOVA with post hoc Dunnett's test $(*, P<0.05 ; * *, P<0.01 ; * * *$, $P<0.001)$. 
A

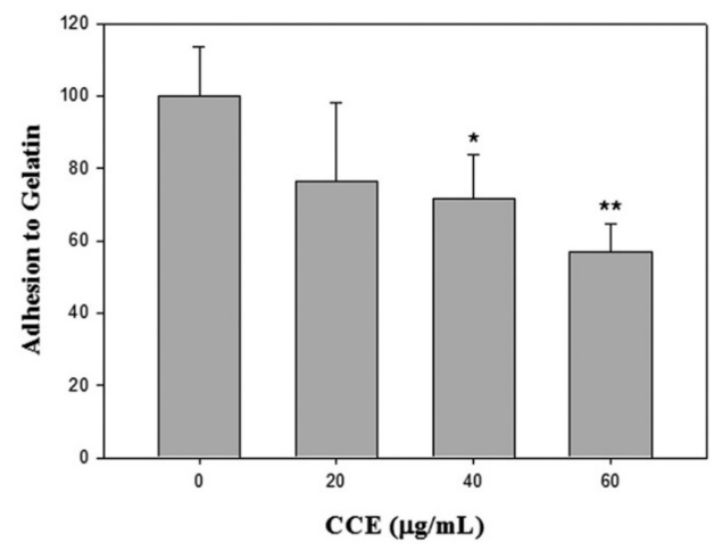

C

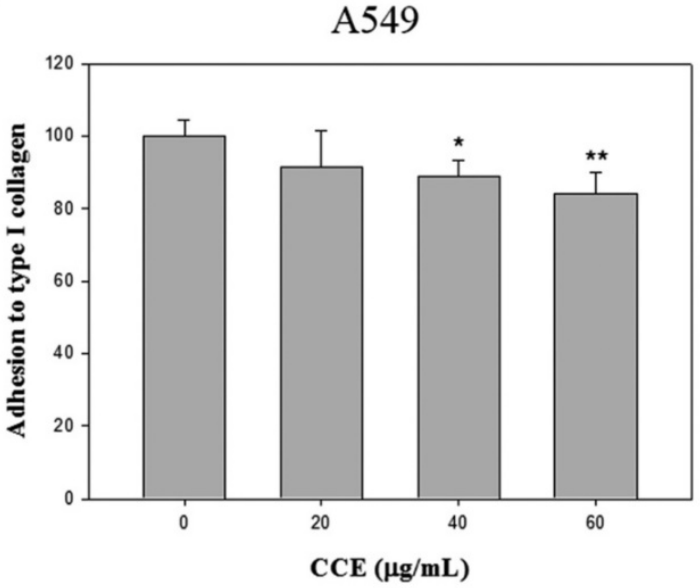

B

H1299

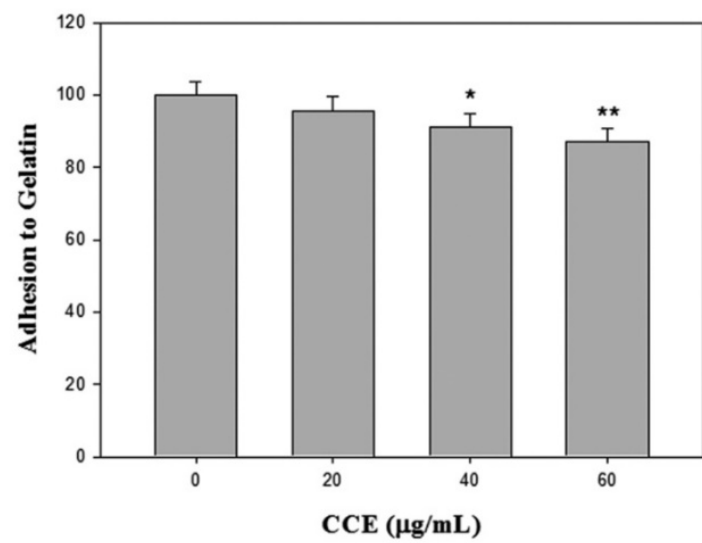

D

H1299

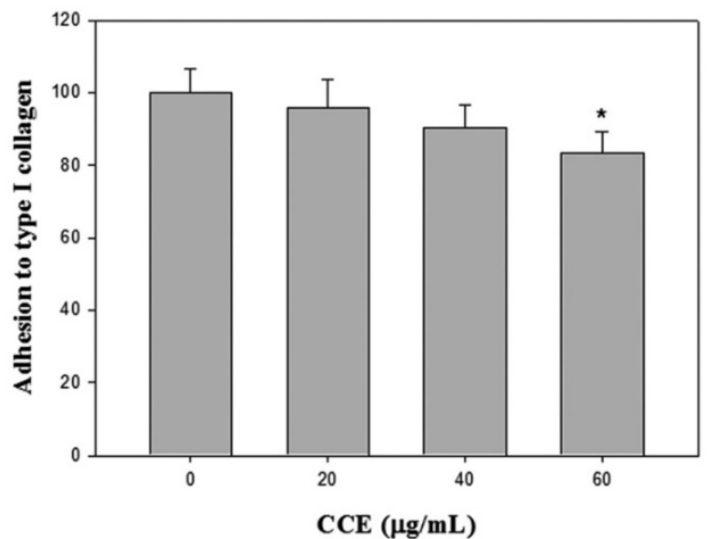

Figure 4. Effects of CCE on cell-matrix adhesion in the human lung cancer cells. The adhesion on (A and B) gelatin and (C and D) collagen type 1 of A549 and H1299 cells was assayed after the cells were treated with different concentration $(0,20,40$, and $60 \mu \mathrm{g} / \mathrm{mL})$ of $C \mathrm{CE}$ for $24 \mathrm{~h}$. Similar results were obtained from three repeated and independent experiments using one-way ANOVA with post hoc Dunnett's test $(*, P<0.05 ; * *, P<0.01)$.

A

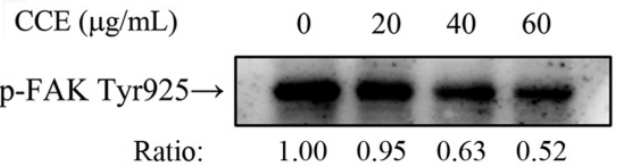

p-FAK Tyr397 $\rightarrow$

Ratio:

$\begin{array}{llll}1.00 & 0.48 & 0.47 & 0.43\end{array}$

$$
\mathrm{t}-\mathrm{FAK} \rightarrow
$$

Ratio:

$\begin{array}{llll}1.00 & 0.99 & 0.99 & 0.99\end{array}$

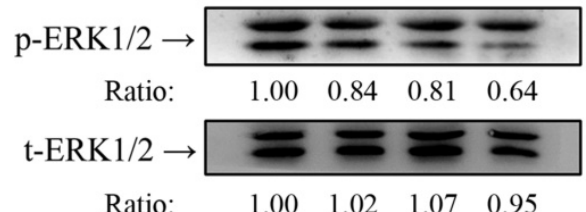

Ratio:

$\begin{array}{llll}1.00 & 1.02 & 1.07 & 0.95\end{array}$
B

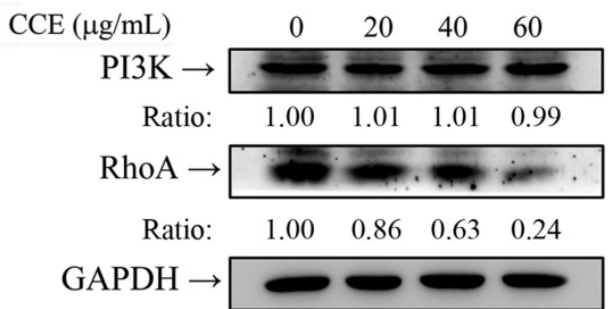

\section{GAPDH $\rightarrow$}

Figure 5. Effects of CCE on the expression of FAK and ERK1/2 in the human lung cancer cells. Expression levels of (A) FAK, ERK, (B) PI3K, and RhoA and their phosphorylation after CCE treatments of A549 cells were measured by Western blot analysis, with GAPDH as the internal control. Similar results were obtained from three repeated and independent experiments using one-way ANOVA with post hoc Dunnett's test $(*, P<0.05 ; * *, P<0.01)$. 


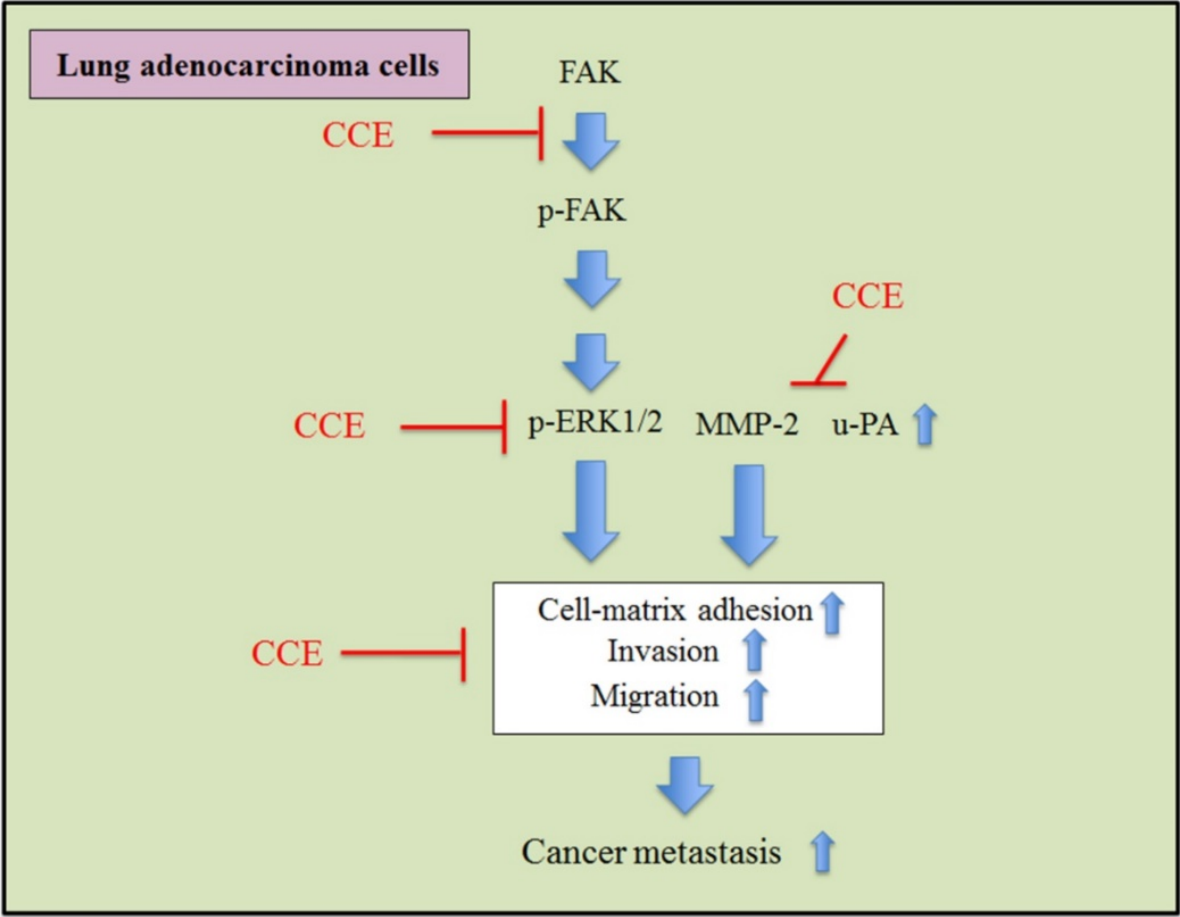

Figure 6. Proposed molecular targets in anti-invasiveness and anti-migration efficacy of CCE in lung cancer cells.

FAK is a focal adhesion-associated protein tyrosine kinase, and the activated p-FAK stimulates the signaling transduction pathway and modulates cancer cell proliferation, survival, motility, adhesion, migration, and invasion $[17,18]$. In the present study, we demonstrated that CCE downregulated phosphorylation of FAK and ERK1/2 in A549 cells, which are essential molecules in MMP production to regulate the degradation of ECM and enhance cell invasion $[19,20]$. These results indicated that p-FAK could mediate the anti-metastasis mechanism of CCE via the ERK1/2 and FAK pathways in A549 cells. RhoA can promote cell proliferation, invasion, and metastasis in some tumors [21]. Interestingly, we observed the downregulation of the RhoA protein expression by CCE in A549 cells, targeting the actin cytoskeleton to further exert anti-metastatic properties.

Chemotherapy has benefits, but the systemic toxicity and side-effects can be traumatic to patient. Thus, the reduction in anticancer drugs-caused systemic toxicity has been a major challenge in maximizing the beneficial outcome of this therapy for cancer. Phytotherapeutic agents with high anti-tumor effect and less toxicity to normal tissues have been suggested as possible candidates for their capability to improve the efficacy of chemotherapeutic agents [22]. In this study, CCE has anti-invasion and anti-migration effects of highly metastatic human lung carcinoma cells, while CCE exerts no cytotoxicity of normal human lung cell lines as a combination medication with adjuvant chemotherapy on human lung cancer patients.

In conclusion, CCE inhibited the phosphorylation of ERK1/2 and FAK and also downregulated MMP-2 and u-PA to inhibit the metastasis of human lung A549 and H1299 cells. The results confirm the hypothesis that CCE possesses anti-cancer properties on lung adenocarcinoma cells, elucidating the mechanism responsible for these effects. This study may also facilitate the identification of a novel therapeutic agent for human lung adenocarcinoma.

\section{Acknowledgements}

This study was financially supported by clinical research grants from Kaohsiung Armed Forces General Hospital, Kaohsiung, Taiwan [105-28] and Ministry of Science and Technology, Taiwan [106-2320-B-040-020-MY3 and 106-2320-B-040 -016].

\section{Competing Interests}

The authors have declared that no competing interest exists.

\section{References}

[1] Valastyan S, Weinberg RA. Tumor metastasis: molecular insights and evolving paradigms. Cell. 2011;147:275-292.

[2] Fatima M, Zaidi NU, Amraiz D, Afzal F. In Vitro Antiviral Activity of Cinnamomum cassia and Its Nanoparticles Against H7N3 Influenza A Virus. J Microbiol Biotechnol. 2016;26:151-159.

[3] Lin CC, Wu SJ, Chang CH, Ng LT. Antioxidant activity of Cinnamomum cassia. Phytother Res. 2003;17:726-730. 
[4] Chang WL, Cheng FC, Wang SP, Chou ST, Shih Y. Cinnamomum cassia essential oil and its major constituent cinnamaldehyde induced cell cycle arrest and apoptosis in human oral squamous cell carcinoma HSC-3 cells. Environ Toxicol. 2017;32:456-468.

[5] Ling F, Jiang C, Liu G, Li M, Wang G. Anthelmintic efficacy of cinnamaldehyde and cinnamic acid from cortex cinnamon essential oil against Dactylogyrus intermedius. Parasitology. 2015;142:1744-1750.

[6] He ZD, Qiao CF, Han QB, Cheng CL, Xu HX, Jiang RW, But PP, Shaw PC. Authentication and quantitative analysis on the chemical profile of cassia bark (cortex cinnamomi) by high-pressure liquid chromatography. J Agric Food Chem. 2005;53:2424-2428.

[7] Rao PV, Gan SH. Cinnamon: a multifaceted medicinal plant. Evid Based Complement Alternat Med. 2014;2014:642942.

[8] Lin CY, Chen PN, Hsieh YS, Chu SC. Koelreuteria formosana extract impedes in vitro human LDL and prevents oxidised LDL-induced apoptosis in human umbilical vein endothelial cells. Food Chem. 2014;146:299-307.

[9] Lu KH, Yang HW, Su CW, Lue KH, Yang SF, Hsieh YS. Phyllanthus urinaria suppresses human osteosarcoma cell invasion and migration by transcriptionally inhibiting u-PA via ERK and Akt signaling pathways. Food Chem Toxicol. 2013;52:193-199.

[10] Yang JS, Lin CW, Hsieh YS, Cheng HL, Lue KH, Yang SF, Lu KH. Selaginella tamariscina (Beauv.) possesses antimetastatic effects on human osteosarcoma cells by decreasing MMP-2 and MMP-9 secretions via p38 and Akt signaling pathways. Food Chem Toxicol. 2013;59:801-807.

[11] Lu KH, Chen PN, Lue KH, Lai MT, Lin MS, Hsieh YS, Chu SC. 2'-hydroxyflavanone induces apoptosis of human osteosarcoma 143 B cells by activating the extrinsic TRAIL- and intrinsic mitochondria-mediated pathways. Nutr Cancer. 2014;66:625-635.

[12] Huang SF, Horng CT, Hsieh YS, Hsieh YH, Chu SC, Chen PN. Epicatechin-3-gallate reverses TGF-beta1-induced epithelial-to-mesenchymal transition and inhibits cell invasion and protease activities in human lung cancer cells. Food Chem Toxicol. 2016;94:1-10.

[13] Hsieh YS, Chu SC, Yang SF, Chen PN, Liu YC, Lu KH. Silibinin suppresses human osteosarcoma MG-63 cell invasion by inhibiting the ERK-dependent c-Jun/AP-1 induction of MMP-2. Carcinogenesis. 2007;28:977-987.

[14] Foroni C, Broggini M, Generali D, Damia G. Epithelial-mesenchymal transition and breast cancer: role, molecular mechanisms and clinical impact. Cancer Treat Rev. 2012;38:689-697.

[15] Kessenbrock K, Plaks V, Werb Z. Matrix metalloproteinases: regulators of the tumor microenvironment. Cell. 2010;141:52-67.

[16] Voulgari A, Pintzas A. Epithelial-mesenchymal transition in cancer metastasis: mechanisms, markers and strategies to overcome drug resistance in the clinic. Biochim Biophys Acta. 2009;1796:75-90.

[17] Brunton VG, Frame MC. Src and focal adhesion kinase as therapeutic targets in cancer. Curr Opin Pharmacol. 2008;8:427-432.

[18] Sulzmaier FJ, Jean C, Schlaepfer DD. FAK in cancer: mechanistic findings and clinical applications. Nat Rev Cancer. 2014;14:598-610.

[19] Page-McCaw A, Ewald AJ, Werb Z. Matrix metalloproteinases and the regulation of tissue remodelling. Nat Rev Mol Cell Biol. 2007;8:221-233.

[20] Park JH, Han HJ. Caveolin-1 plays important role in EGF-induced migration and proliferation of mouse embryonic stem cells: involvement of PI3K/Akt and ERK. Am J Physiol Cell physiol. 2009;297:C935-944.

[21] Huang M, Prendergast GC. RhoB in cancer suppression. Histol Histopathol. 2006;21:213-218.

[22] Chen WT, Yang TS, Chen HC, Chen HH, Chiang HC, Lin TC, Yeh CH, Ke TW, Chen JS, Hsiao KH, Kuo ML. Effectiveness of a novel herbal agent MB-6 as a potential adjunct to 5-fluoracil-based chemotherapy in colorectal cancer. Nutr Res. 2014;34:585-594. 